\title{
Effects of Inhibition of Nitric Oxide Formation on Basal Vasomotion and Endothelium-dependent Responses of the Coronary Arteries in Awake Dogs
}

\author{
Alan Chu, David E. Chambers, Chang-Chyi Lin, William D. Kuehl, Richard M.J. Palmer, \\ Salvador Moncada, ${ }^{*}$ and Frederick R. Cobb \\ Department of Medicine, Division of Cardiology, Duke Medical Center and the Durham Veterans Administration Medical Center, \\ Durham, North Carolina 27705; and the *Wellcome Research Laboratories, Beckenham, United Kingdom
}

\begin{abstract}
The role of nitric oxide in basal vasomotor tone and stimulated endothelium-dependent dilations in the coronary arteries in chronically instrumented awake dogs was studied by examining the consequences of inhibiting endogenous nitric oxide formation with the specific inhibitor of nitric oxide formation, $N^{\mathbf{G}}$ monomethyl-L-arginine (L-NMMA). In four awake dogs, coronary dimension crystals were chronically implanted on the circumflex artery for the measurement of epicardial coronary diameter, and Doppler flow probes were implanted for quantitation of phasic coronary blood flow (vasomotion of distal regulatory resistance vessels). Basal epicardial coronary diameter, acetylcholine-stimulated endothelium-dependent dilation, and flow-induced endothelium-dependent dilation of the epicardial arteries and phasic blood flow were recorded before, and after $5,15,50$, and $120 \mathrm{mg} / \mathrm{kg}$ of L-NMMA. L-NMMA induced a dose-related increase in basal epicardial coronary vasomotor tone. There was an accompanying increase in aortic pressure and a decrease in heart rate. At doses $\geq 50 \mathrm{mg} / \mathrm{kg}$, rest phasic coronary blood flow was also decreased. Left ventricular enddiastolic pressure and contractility were not significantly changed. In contrast, the flow-induced or acetylcholine-stimulated endothelium-dependent responses were attenuated only after infusion of the highest doses of L-NMMA $(120 \mathrm{mg} / \mathrm{kg})$. The changes in the basal vasomotor tone and acetylcholinestimulated endothelium-dependent responses returned towards the control states in the presence of $L$-arginine $(660 \mathrm{mg} / \mathrm{kg})$. These data support the view that nitric oxide plays a significant role in modulating basal vasomotion and endothelial-dependent dilation stimulated by acetylcholine or increase in blood flow in epicardial coronary arteries and also influence the regulation of coronary blood flow during physiologic conditions. (J. Clin. Invest. 1991. 87:1964-1968.) Key words: nitric oxide • coronary vasomotion $\bullet$ awake dogs
\end{abstract}

\section{Introduction}

Since the description by Furchgott and co-workers (1) of endothelium-derived relaxing factor (EDRF), ${ }^{1}$ intensive efforts

Address correspondence to Frederick R. Cobb, M.D., Division of Cardiology (111A), Durham VA Medical Center, 508 Fulton St., Durham, NC 27705 .

Received for publication 1 May 1990 and in revised form 27 December 1990.

1. Abbreviations used in this paper: EDRF, endothelium-derived relaxing factor; L-NMMA, $N^{\mathrm{G}}$-monomethyl-L-arginine.

The Journal of Clinical Investigation, Inc.

Volume 87, June 1991, 1964-1968 have been made to characterize and identify the nature of this biologic mediator (2-5). Increasing evidence suggests that nitric oxide or a closely related compound represents at least one type (if not the only type) of EDRF because both nitric oxide and EDRF have the same biologic and pharmacologic properties $(3,6-8)$ and nitric oxide is released in sufficient quantities to explain the biological actions of $\operatorname{EDRF}(3)$. Other investigators have provided data that suggest nitric oxide may not account for all the actions of EDRF, and that, depending on the vascular bed and the activator, there may be more than one type of EDRF (9-13).

Nitric oxide is synthesized by endothelial cells from the terminal quanidino nitrogen atom of the amino acid L-arginine (14) and $N^{\mathrm{G}}$-monomethyl-L-arginine (L-NMMA) has been shown to inhibit its formation in a concentration-dependent and enantiomerically specific manner (15). In addition, LNMMA increases basal tone in rings of the rabbit aorta (15, 16), guinea pig pulmonary artery (17), and Langendorff perfused rabbit heart preparation (18). Acetylcholine-induced relaxation is also attenuated by L-NMMA in these preparations (16-18). Furthermore, L-NMMA increases mean arterial pressure in anesthetized rabbits and this is associated with reduced release of NO from the perfused aorta of treated animals (19). A similar rise in blood pressure induced by L-NMMA has been reported in guinea pigs (20). More recently, the rise in blood pressure induced by L-NMMA in conscious rats has been shown to be accompanied by a substantial fall in regional blood flow in the renal, mesenteric hindquarters and internal carotid vascular beds (21). The relevance of these findings to man has recently been highlighted by the observation that infusion of L-NMMA into the brachial artery causes vasoconstriction and inhibition of the vasodilation induced by acetylcholine (22). All these effects of L-NMMA are reversed by an excess of L-arginine.

This study was designed to examine the role of endogenous nitric oxide in coronary vasomotion in chronically instrumented awake dogs by evaluating the effects of a wide range of inhibition of endogenous nitric oxide formation by L-NMMA on basal coronary vasomotion and endothelium-dependent stimulated vasodilation by acetylcholine and increases in blood flow.

\section{Methods}

Mongrel dogs $(30-35 \mathrm{~kg})(n=4)$, primarily screened for the absence of anemia and infection, were subjected to left thoracotomy under general anesthesia with intravenous thiamylal sodium $(60-80 \mathrm{mg} / \mathrm{kg})$. Heparin-filled polyvinyl catheters were inserted into the ascending aorta via the left internal thoracic artery, in the left atrium via the atrial appendage and in the left ventricular chamber via the apex. A proximal segment $(0.5-1 \mathrm{~cm})$ of the left circumflex artery just distal to the atrial appendage was dissected minimally. Miniature $7 \mathrm{MHz}$ piezoelectric crystals $(1.5 \times 2.5 \mathrm{~mm}, 15-20 \mathrm{mg})$, attached to a Dacron backing, were 
sutured to the adventitia on opposite surfaces of the vessel segment with 6-0 prolene (Ethicon, Inc., Somerville, NJ). Oscilloscope monitoring and on-line sonomicrometry (Sonomicrometer 120-2; Triton Technology, Inc., San Diego, CA) were used to verify proper crystal alignment. A pulse Doppler flow probe ( $10 \mathrm{MHz}$, cuff type) was implanted distal to the crystals. An inflatable balloon occluder was also placed distal to the flow probe. All arterial branches between the crystals and the occluder were carefully ligated. The catheters and electrode wires were tunnelled to a subcutaneous pouch at the base of the neck.

The dogs were allowed to recover for 10-14 d. The catheters and wires were then exteriorized under lidocaine infiltration anesthesia. On a day before subjecting the dogs to the study protocol, each animal was given a bolus injection of nitroglycerin $(0.04 \mathrm{mg})$ to ensure a responsive vasculature ( $>3 \%$ dilation). On the study day, the dogs were loosely restrained and lying awake on their right side. Aortic pressure, left ventricular end-diastolic pressure, $d P / d t$, external coronary diameter, coronary flow, and electrocardiograms were continuously recorded. Pressure tracings from the fluid-filled catheters were optimally damped with a Corrector device (Norton Health Care Products, Akron, $\mathrm{OH}$ ).

After obtaining the baseline coronary and systemic hemodynamic parameters each dog was subjected to the following two interventions: (a) a bolus injection (left atrial catheter) of acetylcholine (4 $\mu \mathrm{g})$ during constant phasic coronary flow maintained by partial inflation of the pneumatic occluder, and (b) 20-s transient coronary occlusion followed by complete release of the occluder. The 20-s occlusion below the crystal site was used to cause a transient increase in coronary blood flow, the reactive hyperemic response, which in turn was followed by flow-mediated vasodilation of the epicardial coronary artery. At least 15 min were allowed between interventions and the order was randomized. L-NMMA acetate salt (Wellcome Research Laboratories, Beckenham, UK) $(5 \mathrm{mg} / \mathrm{kg}$ dissolved in saline at a concentration of $30-50$ $\mathrm{mg} / \mathrm{ml}$ ), was infused slowly into the left atrium at a rate of $<100 \mathrm{mg} /$ $\mathrm{min}$ to minimize acute hemodynamic changes. At $5 \mathrm{~min}$ after the hemodynamic parameters reached a new steady state, the stimuli for the endothelium-dependent responses (20-s transient occlusion, flow-induced dilation, and acetylcholine injection) were repeated. Subsequently, higher doses of L-NMMA $(15,50,120 \mathrm{mg} / \mathrm{kg})$ were administered in an increasing order. Each administration was followed by a repeat measurement of the basal and the stimulated endothelium-dependent responses. After the stimulated responses after the highest dose of L-NMMA, the nonendothelium-dependent dilator nitroglycerin (0.04 mg) was given as a bolus in the left atrium. After 20-30 minutes, when the basal coronary diameter had returned to the level before nitroglycerin injection, L-arginine $(660 \mathrm{mg} / \mathrm{kg}$ dissolved in saline at 100 $\mathrm{mg} / \mathrm{ml}$ ) (Sigma Chemical Co., St. Louis, MO) was infused slowly over 20-30 min into the left atrium. The basal and stimulated endotheliumdependent responses were again repeated. Nitroglycerin $(0.04 \mathrm{mg})$ was given at the end of the study day.

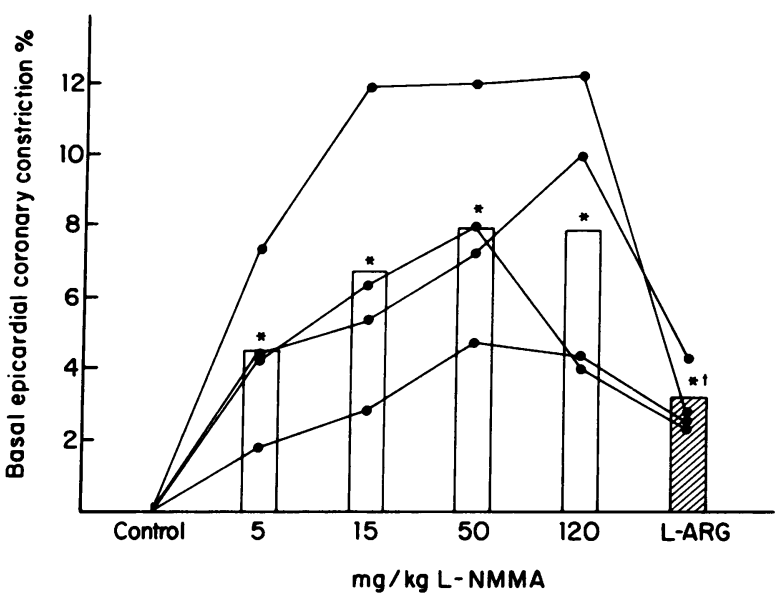

Figure 1. Effects of increasing doses of L-NMMA on basal epicardial coronary vasomotor tone. Individual (circles) and mean (bars) data are plotted as percent change from control. Coronary dimensions decreased in a dose-related fashion after infusion of L-NMMA. L-Arginine partially reversed the response. *Significant when compared with control. ${ }^{\dagger}$ Significant when compared with $120 \mathrm{mg} / \mathrm{kg}$ L-NMMA.

All hemodynamic measurements were compared with measurements obtained before infusion of L-NMMA using the same dog as its own control. Statistical analyses were performed using an analysis of variance for repeated measures.

\section{Results}

Table I summarizes the baseline hemodynamic changes before and after the infusion of each dose of L-NMMA. L-NMMA (5-120 mg/ $\mathrm{kg}$ ) caused dose-related significant increases in mean aortic pressure from a control of $94 \pm 6$ to $129 \pm 15 \mathrm{mmHg}$ after the highest dose of $120 \mathrm{mg} / \mathrm{kg}$. The largest effects of inhibition of endogenous NO production on aortic pressure occurred after the lowest dosages of L-NMMA $5-15 \mathrm{mg} / \mathrm{kg}$, with minimal further increase despite a $>10$-fold increase in L-NMMA dosage. Heart rate decreased from $62 \pm 2$ to $43 \pm 4$ beats/min. At $>15 \mathrm{mg} / \mathrm{kg}$, L-NMMA caused intermittent second- or thirddegree atrioventricular block. Changes in aortic pressure and heart rate were reversed with $L$-arginine. Left ventricular enddiastolic pressure tended to increase from $10 \pm 1$ to $14 \pm 2$

Table I. Resting Hemodynamic Measurements after Increasing Inhibition of Nitric Oxide Formation

\begin{tabular}{|c|c|c|c|c|c|c|}
\hline & \multirow[b]{2}{*}{ Control } & \multicolumn{4}{|c|}{ L-NMMA $(m g / k g)$} & \multirow[b]{2}{*}{ L-Arg } \\
\hline & & 5 & 15 & 50 & 120 & \\
\hline $\begin{array}{l}\text { Aortic pressur } \\
(\mathrm{mmHg})\end{array}$ & $94 \pm 6$ & $114 \pm 4^{*}$ & $120 \pm 7^{*}$ & $121 \pm 11^{*}$ & $129 \pm 15^{*}$ & $104 \pm 5^{\ddagger}$ \\
\hline $\begin{array}{l}\text { Heart rate } \\
\qquad(b p m)\end{array}$ & $62 \pm 2$ & $57 \pm 2^{*}$ & $46 \pm 3^{*}$ & $41 \pm 3^{*}$ & $43 \pm 4^{*}$ & $62 \pm 6^{\ddagger}$ \\
\hline $\begin{array}{l}\text { LVEDP } \\
(m m H g)\end{array}$ & $10 \pm 1$ & $13 \pm 1$ & $14 \pm 1$ & $15 \pm 1$ & $14 \pm 2$ & $11 \pm 1$ \\
\hline $\begin{array}{l}\mathrm{LV} d P / d t \\
\quad(\mathrm{mmH} / \mathrm{s})\end{array}$ & $2483 \pm 306$ & $2500 \pm 153$ & $2533 \pm 167$ & $2467 \pm 213$ & $2633 \pm 120$ & $2817 \pm 117$ \\
\hline
\end{tabular}

Results expressed in mean \pm SEM. LV, left ventricular. EDP, end-diastolic pressure. ${ }^{*}$ Significant when compared with control. ${ }^{\ddagger}$ Significant when compared with measurement at $120 \mathrm{mg} / \mathrm{kg} \mathrm{L-NMMA}$. 


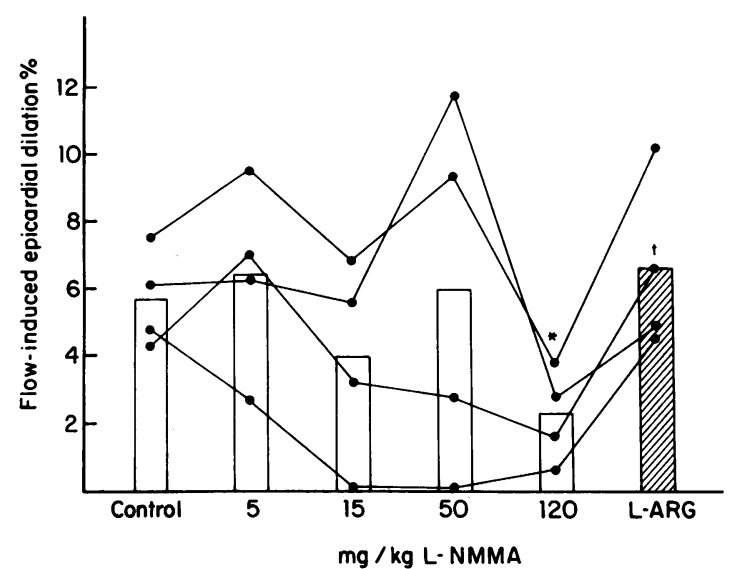

Figure 2. Effects of increasing doses of L-NMMA on flow-induced dilation. Individual (circles) and mean (bars) data are plotted as percent dilation. Although the effects of L-NMMA were variable at lower doses, the reductions were consistent at the $120 \mathrm{mg} / \mathrm{kg}$ dose $\left(^{*}\right)$ when compared with control. L-Arginine reversed the reduction in Ach-induced dilation. ${ }^{\dagger}$ Significant when compared with $120 \mathrm{mg} / \mathrm{kg}$ L-NMMA.

mmHg but the change was not statistically significant. Left ventricular $d P / d t$ was not significantly altered after L-NMMA.

The effects of increasing doses of L-NMMA on basal epicardial coronary dimensions in individual dogs are illustrated in Fig. 1. Although the magnitude of the response was variable in individual animals, L-NMMA-induced dose-related vasoconstriction in each animal. The epicardial diameter decreased from $3.67 \pm 0.10$ to $3.38 \pm 0.06 \mathrm{~mm}$ after the highest dose of L-NMMA representing an $8 \%$ decrease in vessel diameter or $15 \%$ decrease in cross-sectional area. As with aortic pressure, the largest effect of inhibition of endogenous NO production on coronary dimensions occurred after the lower dosages of L-NMMA, with only small changes occurring with dosages $>15 \mathrm{mg} / \mathrm{kg}$. Again, the epicardial vasoconstriction was partially reversed toward control levels with $\mathrm{L}$-arginine.

In contrast to the effect on aortic pressure and basal epicardial dimension flow-induced, endothelium-dependent dilation was not significantly altered after infusions of up to $50 \mathrm{mg} / \mathrm{kg}$ L-NMMA, but was significantly reduced after $120 \mathrm{mg} / \mathrm{kg} \mathrm{L}$ NMMA from $0.209 \pm 0.024 \mathrm{~mm}(5.71 \pm 0.70 \%)$ to $0.076 \pm 0.024$ $\mathrm{mm}(2.26 \pm 0.73 \%)$ (Fig. 2). The response, however, was variable in individual animals; one animal was particularly sensitive to inhibition by L-NMMA. The flow-induced, endothelium-dependent dilation was reversed to control levels after infusion of L-arginine. The maximal epicardial coronary diameter after nitroglycerin was not significantly changed in the presence of $L$-NMMA.

A similar pattern was seen for the acetylcholine-induced, endothelium-dependent dilation which was not significantly inhibited until after infusion of $120 \mathrm{mg} / \mathrm{kg}$ of L-NMMA (control, $0.154 \pm 0.016 \mathrm{~mm}$ or $4.20 \pm 0.48 \%$; L-NMMA, $0.71 \pm 0.008$ or $2.11 \pm 0.21 \%$ ) (Fig. 3). The response also was variable in individual animals. The same animal that demonstrated greater sensitivity to L-NMMA inhibition of flow-induced vasodilation also demonstrated greater sensitivity to L-NMMA inhibition of acetylcholine induced vasodilation. The acetylcholineinduced dilation response was reversed to control levels after infusion of $\mathrm{L}$-arginine.
The effects of L-NMMA on rest phasic coronary blood flow (vasomotion of distal resistance coronary vessels) were modest; maximum decrease was $19 \%$. Although there was a tendency for blood flow to decrease at the $15 \mathrm{mg} / \mathrm{kg}$ dose, because of the variable responses, significance was not achieved until the $\mathbf{5 0}$ $\mathrm{mg} / \mathrm{kg}$ dose (Table II). Peak reactive hyperemic flow-induced after 20 s transient coronary occlusion was, however, not signifcantly different even after the infusion of the highest dose of L-NMMA. Therefore, the reduction of flow-induced epicardial coronary dilation seen after L-NMMA resulted from a direct effect of inhibition of nitric oxide formation rather than secondary to reduced peak flow. L-Arginine reversed the resting flow toward control levels.

\section{Discussion}

The present study is the first to assess the effects of a wide range of inhibition of endogenous nitric oxide production on basal or rest vasomotion and acetylcholine and flow-stimulated endothelium-dependent vasodilation of coronary epicardial conductance vessels and systemic hemodynamics in an intact awake physiologic model. In addition, effects of a wide range of inhibition of endogenous NO production on basal or rest phasic coronary blood, a measure of resistance vessel vasomotion was also assessed. L-NMMA has been demonstrated to inhibit endogenous nitric oxide formation from L-arginine in vitro and in anesthetized preparations $(15,16,18,19)$. Using increasing doses of L-NMMA, the present study demonstrated dose-related decreases in basal epicardial coronary dimensions. The changes in epicardial dimensions were accompanied by increases in aortic pressure and decreases in heart rate. The largest change in epicardial dimensions and aortic pressure occurred with the lower doses of L-NMMA, 5 and $15 \mathrm{mg} / \mathrm{kg}$, with only minimal further change in dimensions or pressure despite $>10$-fold further increase in L-NMMA. At doses of L-NMMA $\geq 50 \mathrm{mg} / \mathrm{kg}$, rest coronary flow was decreased also; the maximum decrease was $\sim 19 \%$. In contrast to the effects on basal vasomotion, the flow-induced or acetylcholine-stimulated, endothelium-dependent dilation responses in the coronary arteries were attenuated only after the highest dose of L-NMMA

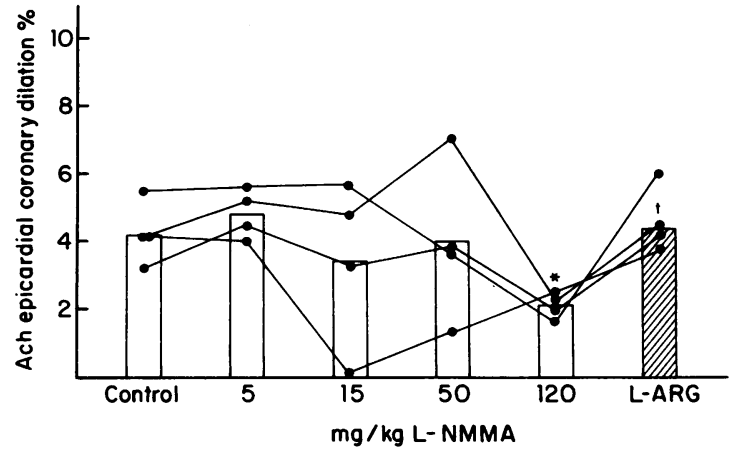

Figure 3. Effects of increasing doses of L-NMMA on acetylcholineinduced dilation. Individual (circles) and mean (bars) data are plotted as percent dilation. Although the effects of L-NMMA were variable at lower doses, the reductions were consistent at the $120 \mathrm{mg} / \mathrm{kg}$ dose $\left(^{*}\right)$ when compared with control. L-Arginine reversed the reduction in Ach-induced dilation. ${ }^{\dagger}$ Significant when compared with $120 \mathrm{mg} / \mathrm{kg}$ L-NMMA. 
Table II. Effects of Increasing Inhibition of Nitric Oxide Formation on Rest and Peak Reactive Hyperemic Flow after a 20-s Occlusion

\begin{tabular}{lcccccr}
\hline & & \multicolumn{5}{c}{ L-NMMA $(\mathrm{mg} / \mathrm{kg})$} \\
\cline { 3 - 6 } & Control & 5 & 15 & 50 & 120 & L-Arg \\
\hline $\begin{array}{l}\text { Rest flow } \\
\quad(K H z)\end{array}$ & $2.18 \pm 0.42$ & $2.09 \pm 0.34$ & $1.76 \pm 0.36$ & $1.78 \pm 0.34^{*}$ & $1.78 \pm 0.30^{*}$ & $1.92 \pm 0.28$ \\
$\begin{array}{l}\text { Peak reactive hyperemic } \\
\text { flow }(\mathrm{KHz})\end{array}$ & $8.37 \pm 0.63$ & $8.68 \pm 0.25$ & $7.91 \pm 0.56$ & $7.21 \pm 0.17$ & $7.32 \pm 0.48$ & $8.92 \pm 0.61$ \\
\hline
\end{tabular}

Results expressed in mean \pm SEM. * Significant when compared with control.

(120 mg/kg). Thus there was a $>20$-fold differential effect of L-NMMA on basal as compared with stimulated epicardial vasomotion. The effects of L-NMMA on rest coronary flow, and flow-induced or acetylcholine-stimulated, endothelium-dependent dilation responses were variable in individual animals; certain animals were affected by lower doses of $\mathrm{L}-\mathrm{NMMA}$. It is possible that with larger number of animals, a statistically significant effect of L-NMMA on these parameters may be achieved at doses $<120 \mathrm{mg} / \mathrm{kg}$. Left ventricular end-diastolic pressure and $d P / d t$ were not significantly altered after L-NMMA. The changes in basal coronary vasomotion and stimulated endothelium-dependent responses were reversed by a high dose of L-arginine. In an earlier study, in a different group of animals, we described the effects of a low dose of L-NMMA, $5 \mathrm{mg} / \mathrm{kg}$ on basal coronary vasomotion (23). The present study extends this initial observation to a wide range of inhibition of NO production and assess effects on stimulated as well as basal vasomotion for the first time.

Previous studies by Amezcua et al. (18) demonstrated that L-NMMA, at a dose between 10 and $100 \mu \mathrm{M}$, produced a doserelated sustained increase in coronary perfusion pressure (resistance coronary artery vasomotion) in a Langendorff-perfused rabbit heart preparation. In the Langendorff preparation, acetylcholine $(0.3 \mu \mathrm{M})$ caused a decrease (vasodilation) before and an increase (vasoconstriction) in coronary perfusion pressure after inhibition of nitric oxide formation. In our present study, we observed that as compared to basal coronary vasomotion, the flow-induced and acetylcholine-stimulated coronary endothelium-dependent responses required a 20-fold higher dose of L-NMMA for significant inhibition. Rees et al. (16) also demonstrated similar effects in in vitro rabbit aortic ring preparations after inhibition of nitric oxide formation on endothelium-dependent relaxations induced by acetylcholine, calcium ionophore, or substance $\mathrm{P}$. In that study, the concentration of $\mathrm{L}$ NMMA that produced $50 \%$ contraction of the rings was six times lower than that required to achieve $50 \%$ inhibition of acetylcholine-induced relaxation (16). Although the reason for this difference between basal and stimulated responses is not known, several possibilities may be considered. The stimulated as compared to basal responses may increase mobilization of the stored substrate within the endothelial cells that required higher concentrations of inhibitor for blockade (16). An alternative explanation may be the presence of more than one EDRF unrelated to nitric oxide: nitric oxide may be the EDRF primarily responsible for modulating basal coronary and peripheral vasomotor tone whereas other EDRFs may contribute to stimulated responses. The fact that a substantial portion (>50\%) of the stimulated responses was inhibited at the higher doses of L-NMMA argues against this possibility.
Coronary blood flow was decreased when the dose of LNMMA was $50 \mathrm{mg} / \mathrm{kg}$ or greater. Because aortic pressure increased with the lowest dose of L-NMMA and coronary flow was unchanged, distal coronary vascular resistance was elevated even after the initial dose of L-NMMA. Previous studies from our laboratory have demonstrated that cyclic guanosine monophosphate-mediated dilators such as EDRF, nitrates, and atrial natriuretic peptide preferentially dilate proximal conductance arteries as compared to distal regulatory resistance coronary arteries in awake dogs (24-27). The vasomotor state of the distal resistance vasculature is influenced by the dominant effects of local myocardial metabolic demands (28). Because nitric oxide has been demonstrated to mediate its vasodilator effects through activation of guanylate cyclase (29, 30 ), it is reasonable to speculate that the increased vasomotor tone of the distal regulatory resistance arteries (as a result of inhibition of nitric oxide formation) may have been overridden by the dominant vasodilating stimuli mediated by increased myocardial metabolic demands. The lack of significant change in peak hyperemic flow also indicates that the coronary reserve for increasing blood flow was present and that the reduction in flow-induced dilation of the proximal epicardial arteries after L-NMMA is a direct effect of inhibition of nitric oxide formation and not secondary to a difference in the flow stimuli. In recent studies, Vallance et al. (22) observed that infusion of L-NMMA into the brachial artery of healthy volunteers caused a 50\% decrease in basal blood flow and attenuation of the dilator response to acetylcholine but not nitrates suggesting that endothelial-derived nitric oxide influences basal and stimulated limb blood flow in man.

The persistent dose-dependent hypertensive effect seen after L-NMMA in the present study is consistent with the observations of Rees et al. (19) who reported a sustained (15-90 $\mathrm{min}$ ) dose-dependent increase in mean systemic arterial pressure after infusion of L-NMMA $(3-100 \mathrm{mg} / \mathrm{kg})$ in anesthetized rabbits. Indomethacin, prazosin, or vagomotomy did not alter the hypertensive response to L-NMMA (19), whereas it was reversed by L-arginine, as in our present study. The hypertensive response to L-NMMA probably contributed to the decrease in heart rate seen after the lower doses used in our study (Table I). Second- and third-degree atrioventricular blood was observed after the $15-50 \mathrm{mg} / \mathrm{kg}$ dose which may have been influenced by the increase in blood pressure and/or a direct effect of inhibition of nitric oxide production or L-NMMA on the AV node. The effects on pressure, heart rate, and atrioventricular conduction were reversed by $L$-arginine.

In summary, the results from the present study support the view that endogenous nitric oxide plays a significant physiologic role in modulating basal vasomotor tone in the proximal 
epicardial coronary arteries and distal regulatory resistance coronary vessels. These data also demonstrate that endogenous nitric oxide plays a role in the endothelium-dependent dilation induced by increases in flow or acetylcholine in the epicardial coronary vessels. The effects of endogenous NO on epicardial dimension and aortic pressure were more sensitive to inhibition by L-NMMA with largest change occurring at the lower dosage, whereas the effect on endothelium-dependent stimulated vasodilation occurred consistently at a $>20$-fold higher dose of L-NMMA.

\section{Acknowledgments}

We would like to thank Mr. Joe Long for technical assistance, Medical Media Service for illustrations, and Ms. Cathie Collins for her expert secretarial assistance.

Supported in part by Grants IROL HL 17670 and HL 42562 from the National Heart, Lung and Blood Institute, Bethesda, MD, and from the Research Service, Veterans Administration Medical Center. Alan Chu is supported by a Career Development Award by the Veterans Administration.

\section{References}

1. Furchgott, R. F., and J. V. Zawadzki. 1980. The obligatory role of endothelial cells in the relaxation of arterial smooth muscle by acetylcholine. Nature (Lond.). 288:373-376.

2. Furchgott, R. F. 1983. Role of endothelium in responses of vascular smooth muscle. Circ. Res. 53:557-573.

3. Moncada, S., M. W. Radomski, and R. M. J. Palmer. 1988. Endotheliumderived relaxing factor: identification as nitric oxide and role in the control of vascular tone and platelet function. Biochem. Pharmacol. 37:2495-2501.

4. Furchgott, R. F., and P. M. Vanhoutte. 1989. Endothelium-derived relaxing and contracting factors. FASEB (Fed. Am. Soc. Exp. Biol.) J. 3:2007-2018.

5. Ignarro, L. J. 1989. Biological action and properties of endothelium-derived nitric oxide formed and released from artery and vein. Circ. Res. 65:1-21.

6. Furchgott, R. F. 1987. Studies on relaxation of rabbit aorta by sodium nitrite: the basis for the proposal that the acid-activatable inhibitory factor from bovine retractor penis is inorganic nitrite and the endothelium-derived relaxing factor is nitric oxide. In Mechanisms of Vasodilation. P. M. Vanhoutte, editor. Raven Press, New York, 401-414.

7. Ignarro, L. J., R. E. Byrns, and K. S. Wood. 1988. Biochemical and pharmacological properties of endothelium-derived relaxing factor and its similarity to nitric oxide radical. In Mechanisms of Vasodilation. P. M. Vanhoutte, editor. Raven Press, New York, 427-435.

8. Palmer, R. M. J., A. G. Ferrige, and S. Moncada. 1987. Nitric oxide release accounts for the biological activity of endothelium-derived relaxing factor. $\mathrm{Na}$ ture (Lond.). 327:524-526.

9. Rubanyi, G. M., and P. M. Vanhoutte. 1987. Nature of endothelium-derived relaxing factor: are there two relaxing mediators? Circ. Res. 61(Suppl. II):II61-II67.

10. Boulanger, C., H. Hendrickson, R. R. Lorenz, and P. M. Vanhoutte. 1989. Release of different relaxing factors by cultured porcine endothelial cells. Circ. Res. 64:1070-1078.

11. Shikano, K., E. H. Ohlstein, and B. A. Berkovitz. 1987. Differential selec- tivity of endothelium-derived relaxing factor and nitric oxide in smooth muscle. Br. J. Pharmacol. 92:483-485.

12. Kontos, H. A., E. P. Wei, J. T. Povlishock, and C. W. Christman. 1984. Oxygen radicals mediate the cerebral arteriolar dilation from arachidonate and bradykinin in cats. Circ. Res. 55:295-303.

13. Myers, P. R., R. Guerra, Jr., and D. G. Harrison. 1989. Release of NO and EDRF from cultured bovine aortic endothelial cells. Heart Circ. Physiol. 25:H1030-H1037.

14. Palmer, R. M. J., D. S. Ashton, and S. Moncada. 1988. Vascular endothelial cells synthesize nitric oxide from L-arginine. Nature (Lond.). 333:664-666.

15. Palmer, R. M. J., D. D. Rees, D. S. Ashton, and S. Moncada. 1988. L-Arginine is the physiological precursor for the formation of nitric oxide in endothelium-dependent relaxation. Biochem. Biophys. Res. Commun. 153:1251-1256.

16. Rees, D. D., R. M. J. Palmer, H. F. Hodson, and S. Moncada. 1989. A specific inhibitor of nitric oxide formation from L-arginine attenuates endothelium-dependent relaxation. Br. J. Pharmacol. 96:418-424.

17. Sakuma, I., D. J. Stuehr, S. S. Gross, C. Nathan, and R. Levi. 1988. Identification of arginine as a precursor of endothelium-derived relaxing factor. Proc. Natl. Acad. Sci. USA. 85:8864-8867.

18. Amezcua, J. L., R. M. J. Palmer, B. M. deSouza, and S. Moncada. 1989. Nitric oxide synthesized from L-arginine regulates vascular tone in the coronary circulation of the rabbit. Br. J. Pharmacol. 97:1019-1024.

19. Rees, D. D., R. M. J. Palmer, and S. Moncada. 1989. Role of endothelium-derived nitric oxide in the regulation of blood pressure. Proc. Natl. Acad. Sci. USA. 86:3375-3378.

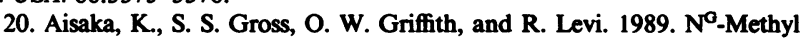
arginine, an inhibitor of endothelium-derived nitric oxide synthesis is a potent pressor agent in the guinea pig: does nitric oxide regulate blood pressure in vivo? Biochem. Biophys. Res. Commun. 160:881-886.

21. Gardiner, S. M., A. M. Compton, T. Bennett, R. M. J. Palmer, and S. Moncada. 1991. Control of regional blood flow by endothelium-dependent nitric oxide. Hypertension (Dallas). In press.

22. Vallance, P., J. Collier, and S. Moncada. 1989. Effects of endotheliumderived nitric oxide on peripheral arteriolar tone in man. Lancet. 334:997-100.

23. Chu, A., D. Chambers, C.-C. Lin, W. Kuehl, and F. R. Cobb. 1990. Nitric oxide modulates epicardial coronary basal vasomotor tone in awake dogs. Am. J. Physiol. 258(Heart Circ. Physiol. 27):H1250-H1254.

24. Chu, A., and F. R. Cobb. 1987. Effects of atrial natriuretic peptide on proximal epicardial coronary arteries and coronary blood flow in conscious dogs. Circ. Res. 61:485-491.

25. Chu, A., J. J. Murray, W. Kuehl, C.-C. Lin, M. Russell, P.-O. Hagen, and F. R. Cobb. 1990. Preferential proximal coronary dilation by activators of guanylate cyclase in awake dogs. Am. J. Physiol. 259(Heart Circ. Physiol. 28):H340H345.

26. Chu, A., F. R. Cobb, P.-O. Hagen, and J. J. Murray. 1989. Effects of a stabilized endothelium-derived relaxing factor on the coronary vasculature in awake dogs. Am. J. Physiol. 257(Heart Circ. Physiol. 26):H1895-H1899.

27. Chu, A., K. G. Morris, W. D. Kuehl, J. Cusma, F. Navetta, and F. R. Cobb. 1989. Effects of atrial natriuretic peptide on the coronary arterial vasculature in humans. Circulation. 80:1627-1635.

28. Rubio, R., and R. M. Byrns. 1975. Regulation of coronary blood flow. Prog. Cardiovasc. Dis. 18:105-135.

29. Ignarro, L. J., G. M. Buga, K. S. Wood, R. E. Byrns, and G. Chadhuri. 1987. Endothelium-derived relaxing factor produced and released from artery and vein is nitric oxide. Proc. Natl. Acad. Sci. USA. 84:9265-9269.

30. Ignarro, L. J., R. E. Byrns, G. M. Buga, K. S. Wood, and G. Chadhuri. 1988. Pharmacological evidence that endothelium-derived relaxing factor is nitric oxide: use of pyrogallol and superoxide dismutase to study endothelium-dependent and nitric oxide-elicited vascular smooth muscle relaxation. J. Pharmacol. Exp. Ther. 244:181-189. 